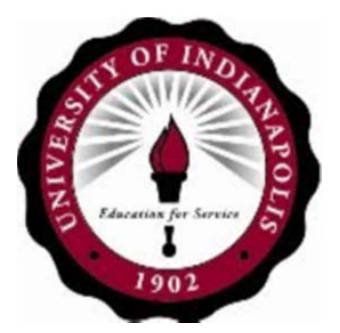

\title{
Ethnic Differences in Spirituality, Shame, and Stigma in People Living with HIV
}

Nicole M. Taylor, Ph.D. ${ }^{1}$, Erin M. Fekete, Ph.D. ${ }^{1}$, Matthew D. Skinta ${ }^{3}$, Stacey L. Williams ${ }^{2}$, Ph.D.

${ }^{1}$ University of Indianapolis, ${ }^{2}$ East Tennessee State University, ${ }^{3}$ Private Practice, San Francisco, CA

First Author Contact Information: ntaylor@uindy.edu

\section{ABSTRACT}

We hypothesized that the links between spirituality and Wor HIV-related stigma would be accounted for by lower levels of shame, and that this mediation model would be moderated by ethnicity in 106 people living with HIV (PLWH). Moderated mediation analyses revealed that higher spirituality was associated with reduced levels of shame, which in turn was associated with lower levels of HIV-related stigma. The indirect effect of spirituality on lower stigma through reduced shame was significant for White but not for Non-White PLWH. It is possible that other mechanisms exist to explain how spirituality operates on stigma for minorities living with HIV.

\section{INTRODUCTION}

HIV is still a highly stigmatized illness.

- People living with HIV (PLWH) experience

higher levels of shame and stigma as a result of their illness diagnosis.

The health benefits of spirituality in PLWH particularly those from ethnic minority

populations, have been well-documented.

- Increased psychological well-being, quality of life, better health behaviors, and longer

survival rates.

- It is also possible that being more spiritual is linked to reduced feelings of shame about one's HIV-illness.

Lower levels of shame may relate to lower perceptions or experiences of HIV-related stigma.

\section{HYPOTHESES}

We hypothesized that the links between spirituality and lower HIV-related stigma would be accounted for by lower levels of shame.

Further, we expected that this mediation model would be moderated by ethnicity (White versus Non-White).

- The relationship between spirituality, lower shame, and reduced stigma would be

stronger for Non-White PLWH than White PLWH.

PARTICIPANTS (N = 106)
\begin{tabular}{|l|l|}
\hline Age (Years) & Mean $=42.6$ \\
\hline Gender & $66 \%$ male, $44 \%$ female \\
\hline Ethnicity & $\begin{array}{l}35.8 \% \text { White; } 64.2 \% \text { Non-White }(48.2 \% \\
\text { Black, 13.2\% Hispanic, 2.8\% Biracial) }\end{array}$ \\
\hline Education & $\begin{array}{l}\text { Did Not Graduate High School = 5.7\%, } \\
\text { High School Graduate }=74.5 \%, \\
\text { College Graduate }=19.8 \%\end{array}$ \\
\hline Yearly Income & Median = $\$ 10,000-\$ 14,999$ \\
\hline $\begin{array}{l}\text { Years since HIV } \\
\text { diagnosis }\end{array}$ & Mean = 11.2 years \\
\hline
\end{tabular}

\section{PROCEDURE}

- Eligibility Criteria

- At least 18 years of age.

Diagnosed by a doctor with HIV or AIDS.

- Valid email address.

Participants completed an online questionnaire

and were compensated with a $\$ 20.00$ gift card.

- Measures included:

- Demographic Information

- Ironson-Woods Spirituality/Religiousness Index (Ironson et al., 2002)

Internalized Shame Scale (Rosario \& White, 2006)

- HIV Stigma Scale (Berger, Ferrans, \& Lashley, 2001)

\section{MEASURES}

\begin{tabular}{|l|c|c|c|c|c|}
\hline \multicolumn{1}{|c|}{ Measure } & Mean & SD & $\begin{array}{c}\text { Actual } \\
\text { Range }\end{array}$ & $\begin{array}{c}\text { Potential } \\
\text { Range }\end{array}$ & $\boldsymbol{\alpha}$ \\
\hline Spirituality & 77.71 & 26.3 & $22-110$ & $22-110$ & .98 \\
\hline $\begin{array}{l}\text { Internalized } \\
\text { Shame }\end{array}$ & 73.29 & 26.5 & $28-139$ & $28-140$ & .96 \\
\hline HIV-Stigma & 97.53 & 25.4 & $43-153$ & $41-164$ & .96 \\
\hline
\end{tabular}

\section{ANALYSIS PLAN}

- Analysis of Covariance (ANCOVA)

- Examine ethnic differences in key study variables after accounting for covariates.

- Moderated Mediation Analysis

- Examine the conditional indirect effects of the predictor on the outcome variable through the mediator at differing levels of

- Continuous predictor and mediator variables were centered to protect against multicollinearity.

-Covariates

- Any ethnic differences in sociodemographic

health, or social characteristics.

- Any sociodemographic, health, or social characteristics associated with the outcome variable after partialling out covariates due to ethnic differences.

\section{ETHNIC DIFFERENCES IN}

KEY STUDY VARIABLES

- No differences emerged between Whites and Non-Whites in spirituality, internalized shame, or HIV-related stigma.

\begin{tabular}{|c|c|c|c|c|}
\hline Variable & $\begin{array}{c}\text { White } \\
\mathrm{n}=\mathbf{3 8} \\
\text { Adj. M (SD) }\end{array}$ & $\begin{array}{c}\begin{array}{c}\text { Non- } \\
\text { White } \\
\mathrm{n}=68 \\
\text { Adj. M } \\
\text { (SD) }\end{array} \\
\end{array}$ & $\begin{array}{c}\mathrm{F}- \\
\text { value }\end{array}$ & $\begin{array}{c}\text { Partial } \\
\mathrm{Eta}^{2}\end{array}$ \\
\hline Spirituality & $80.39(4.4)$ & 76.23 (3.2) & .53 & .01 \\
\hline $\begin{array}{l}\text { Internalized } \\
\text { Shame }\end{array}$ & $78.63(4.6)$ & 70.31 (3.3) & 1.95 & .02 \\
\hline HIV-Stigma & $104.21(4.3)$ & $93.80(3.1)$ & 3.40 & .03 \\
\hline
\end{tabular}

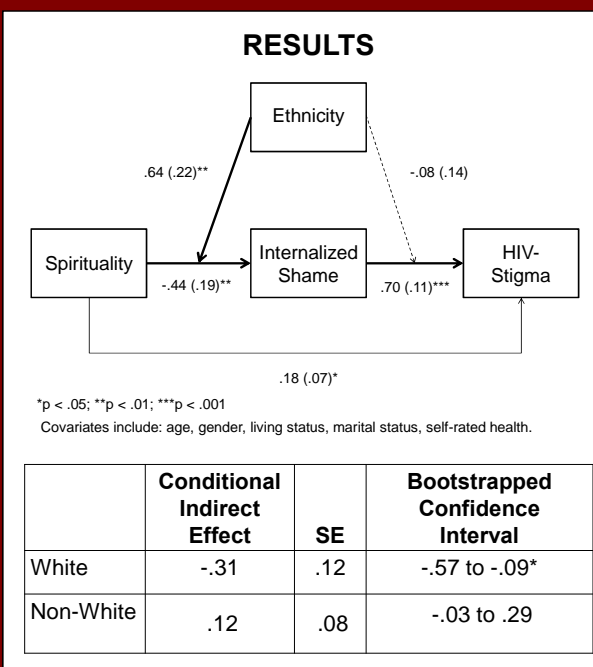

Index of Moderated Mediation $=.43(.14)$ Bootstrapped Confidence Interval $=.17$ to $.75^{*}$

Internalized shame partially mediated the relationship between spirituality and HIV-related stigma, and this relationship was moderated by ethnicity

\section{DISCUSSION}

- Higher levels of spirituality, including religiosity faith, and peace are related to reduced levels of shame in White men and women living with HIV, which in turn is associated with less HIVrelated stigma.

- It is possible that other mechanisms, such as social support or a sense of purpose, explain how spirituality operates on stigma for minorities living with HIV.

- Interventions aimed at reducing HIV-related stigma should acknowledge the importance of spirituality for both minority and non-minority individuals living with HIV. 